\title{
Monitoring performance of sites within multicentre randomised trials: a systematic review of performance metrics
}

\author{
Kate F. Walker ${ }^{*}$ (D), Julie Turzanski, Diane Whitham, Alan Montgomery and Lelia Duley
}

\begin{abstract}
Background: Large multicentre trials are complex and expensive projects. A key factor for their successful planning and delivery is how well sites meet their targets in recruiting and retaining participants, and in collecting highquality, complete data in a timely manner. Collecting and monitoring easily accessible data relevant to performance of sites has the potential to improve trial management efficiency. The aim of this systematic review was to identify metrics that have either been proposed or used for monitoring site performance in multicentre trials.

Methods: We searched the Cochrane Library, five biomedical bibliographic databases (CINAHL, EMBASE, Medline, PsychINFO and SCOPUS) and Google Scholar for studies describing ways of monitoring or measuring individual site performance in multicentre randomised trials. Records identified were screened for eligibility. For included studies, data on study content were extracted independently by two reviewers, and disagreements resolved by discussion.

Results: After removing duplicate citations, we identified 3188 records. Of these, 21 were eligible for inclusion and yielded 117 performance metrics. The median number of metrics reported per paper was 8 , range 1-16. Metrics broadly fell into six categories: site potential; recruitment; retention; data collection; trial conduct and trial safety.

Conclusions: This review identifies a list of metrics to monitor site performance within multicentre randomised trials. Those that would be easy to collect, and for which monitoring might trigger actions to mitigate problems at site level, merit further evaluation.
\end{abstract}

Keywords: Multicentre, Randomised trials, Clinical trials, Performance metrics, Trial management, Site performance, Operational metrics, Key performance indicators

\section{Background}

Multicentre randomised trials are complex and expensive projects. Improving the efficiency and quality of trial conduct is important, for patients, funders, researchers, clinicians and policy-makers [1]. A key factor in successful planning and delivery of multicentre trials is how well sites meet their targets in recruiting and retaining participants, and in collecting high-quality, complete data in a timely manner [2]. Collecting and monitoring easily accessible data relevant to performance of sites has the potential to improve the efficiency and success of trial management. Ideally, such performance metrics should provide information that quickly identifies potential problems so they

\footnotetext{
* Correspondence: kate.walker@nottingham.ac.uk

Nottingham Clinical Trials Unit, QMC, Nottingham NG7 2UH, UK
}

can be mitigated or avoided, hence minimising their impact and improving the efficiency of trial conduct.

We are not aware of any standardised metrics for monitoring site performance in multicentre trials. A recent query to all UK Clinical Research Collaboration (UKCRC), registered Clinical Trials Units (CTUs) revealed that many units routinely collect and report data for each site in a trial; such as numbers randomised, case report forms (CRFs) returned, data quality, missing primary outcome data, and serious breaches. How such data are used to assess and manage performance varies widely however [3-7]. Agreeing a small number of metrics for site performance that could be easily collected, presented and monitored in a standardised way by a trial manager or trial co-ordinator would be a potentially useful tool to improve efficient trial conduct.

(C) The Author(s). 2018 Open Access This article is distributed under the terms of the Creative Commons Attribution 4.0 International License (http://creativecommons.org/licenses/by/4.0/), which permits unrestricted use, distribution, and reproduction in any medium, provided you give appropriate credit to the original author(s) and the source, provide a link to the Creative Commons license, and indicate if changes were made. The Creative Commons Public Domain Dedication waiver (http://creativecommons.org/publicdomain/zero/1.0/) applies to the data made available in this article, unless otherwise stated. 
Currently, trial teams, sponsors, funders and oversight committees monitor site performance and trial conduct based primarily on recruitment [8]. Whilst clearly important, recruitment is not the only performance indicator that matters for a successful trial. Using a range of additional metrics that include data quality, protocol compliance and participant retention would give a better overall measure of the performance of each trial site, and the trial overall. To be low cost and efficient, the number of metrics monitored at any one time should be limited to no more than 8 to 12 [9]. We conducted a systematic review to identify performance metrics that have been used, or proposed, for monitoring or measuring performance at sites in multicentre randomised trials.

\section{Methods}

We performed a systematic review to identify metrics that have been used or proposed for monitoring or measuring performance at individual sites in multicentre randomised trials.

\section{Criteria for potentially eligible studies}

Studies were potentially eligible for inclusion if they:

- Reported one or more site performance metric, either used or proposed for use, specifically for the purpose of measuring individual site performance

- Were multicentre randomised trials, or concerning multicentre trials

- Were published in English

- Related to randomised trials involving humans

Studies where the strategy for monitoring site performance was randomly allocated were included. We anticipated that there might be studies where the adoption of an individual performance metric might have been tested by randomly allocating sites to using that particular metric or not. Studies relevant to both publically funded and industry-funded trials were included.

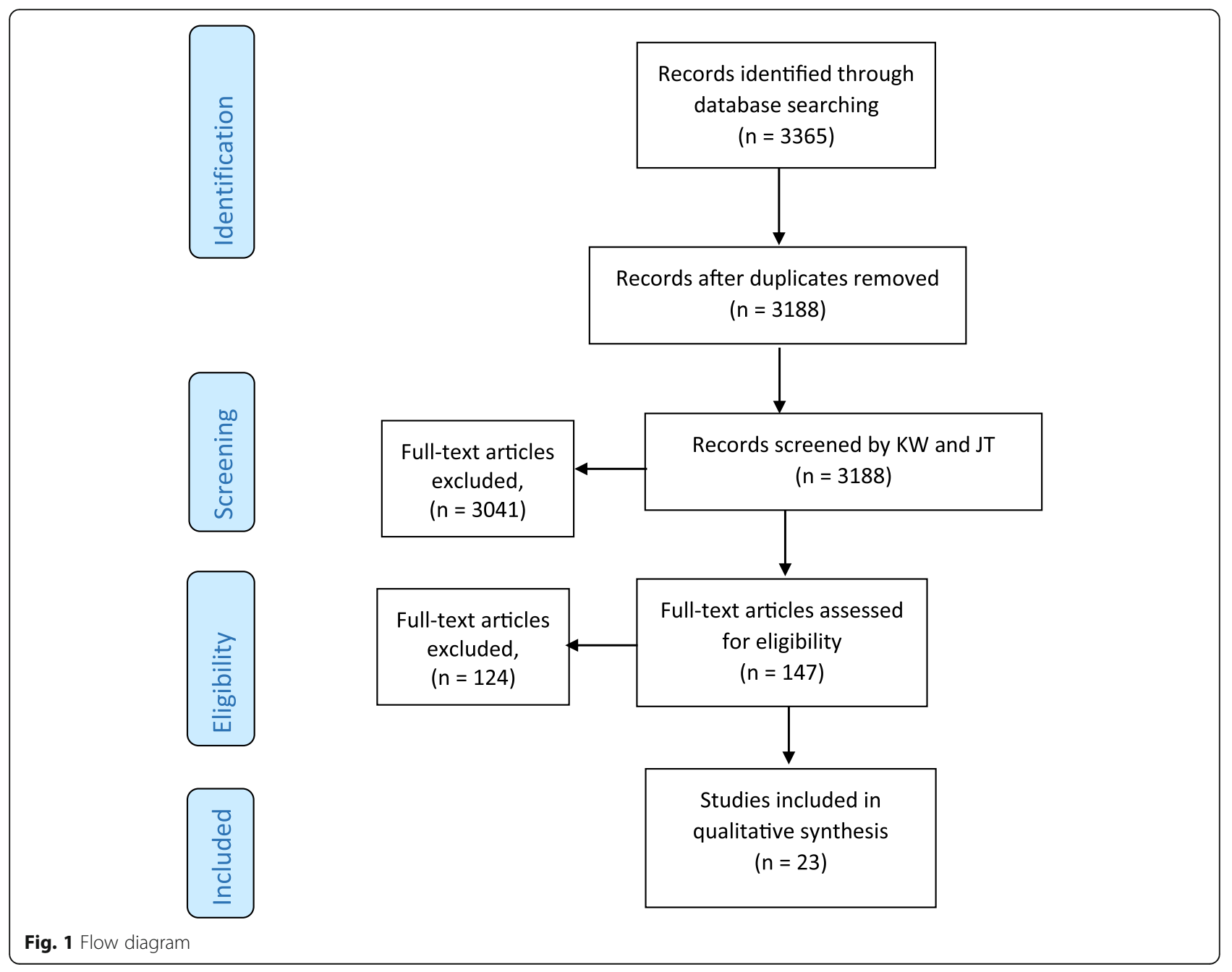


Table 1 Characteristics of included studies

\begin{tabular}{|c|c|c|c|c|}
\hline \multirow[t]{2}{*}{ Study } & \multirow[t]{2}{*}{ Study description } & \multirow{2}{*}{$\begin{array}{l}\text { Number of sites } \\
\text { (sample size) }\end{array}$} & \multicolumn{2}{|l|}{ Metrics reported by each study } \\
\hline & & & $\begin{array}{l}\text { Included as site performance } \\
\text { metric }\end{array}$ & Excluded as not site performance $n$ \\
\hline \multicolumn{5}{|c|}{ Studies proposing performance metrics } \\
\hline Bose 2012 [14] & $\begin{array}{l}\text { Paper discussing trial management } \\
\text { through central monitoring }\end{array}$ & Not applicable & $\begin{array}{l}\text { - Site location potential index } \\
\text { based on an assessment of } \\
\text { the number of patients at an } \\
\text { individual site with the disease } \\
\text { of interest } \\
\text { - Trial compliance index based } \\
\text { on a number of suggested factors } \\
\text { including the number of late visits, } \\
\text { failure to achieve recruitment target, } \\
\text { number of dosing errors, etc. }\end{array}$ & $\begin{array}{l}\text { - Drug adversity measurement (B) } \\
\text { - Drug potential index (B) }\end{array}$ \\
\hline Djali 2010 [15] & $\begin{array}{l}\text { Paper discussing a data-driven } \\
\text { quality management system }\end{array}$ & Not applicable & $\begin{array}{l}\text { - Enrolment number per site } \\
\text { - Recruitment period per site } \\
\text { - Number of AEs per site } \\
\text { - Number of protocol deviations } \\
\text { and violations per site }\end{array}$ & $\begin{array}{l}\text { - Number of discontinuations per } \\
\text { site }(A) \\
\text { - Deaths per site (D) }\end{array}$ \\
\hline Elsa 2011 [16] & $\begin{array}{l}\text { Methodology of developing 'key risk } \\
\text { indicators' for monitoring of a large } \\
\text { international clinical trial }\end{array}$ & Not applicable & $\begin{array}{l}\text { - Rate of SAE reporting per site: } \\
\text { centres assigned a dichotomous } \\
\text { score depending on whether } \\
\text { they showed extreme deviation } \\
\text { from comparable sites (arbitrarily } \\
\text { defined as half the observed } \\
\text { median rate across sites) } \\
\text { - Short visit duration: centres assigned } \\
\text { a dichotomous score depending on } \\
\text { whether they showed extreme } \\
\text { deviation from comparable sites } \\
\text { (arbitrarily defined as half the observed } \\
\text { median rate across sites) }\end{array}$ & $\begin{array}{l}\text { - Measures of compliance with } \\
\text { study treatment (A) } \\
\text { - Blood results/other continuous } \\
\text { variables examined for unusual } \\
\text { patterns (A) }\end{array}$ \\
\hline Glass 2007 [17] & $\begin{array}{l}\text { Study analysing data retrospectively } \\
\text { from } 262 \text { clinical trials to determine } \\
\text { variables associated with successful } \\
\text { trial delivery }\end{array}$ & Not applicable & $\begin{array}{l}\text { - Actual number participants randomised } \\
\text { per site } \\
\text { - Number successfully completing the } \\
\text { study's protocol per site } \\
\text { - Time between when an individual site } \\
\text { randomises its first participant and the } \\
\text { time the first site in that study enrols its } \\
\text { first patient }\end{array}$ & \\
\hline Hanna, 2013 [11] & $\begin{array}{l}\text { Development of a list of quality } \\
\text { indicators for trial performance } \\
\text { based on the consensus of experts }\end{array}$ & Not applicable & $\begin{array}{l}\text { - SAE reporting measured by the number } \\
\text { of SAEs reported/number of SAEs identified } \\
\text { in trial database or trial follow-up documents } \\
\text { - Transfer of CRF to CTU measured by the } \\
\text { number of completed CRF received by CTU } \\
\text { within } 30 \text { days/number of completed CRF } \\
\text { received by the CTU in } 3 \text { months }\end{array}$ & \\
\hline Jou, 2013 [18] & $\begin{array}{l}\text { Aim of the main study: treatment-naïve, } \\
\text { hepatitis } C \text { patients randomised to two } \\
\text { peginterferon regimens. Primary } \\
\text { outcome virologic response. A } \\
\text { retrospective analysis was performed } \\
\text { of individual site performance using } \\
\text { trial data }\end{array}$ & $118(3070)$ & $\begin{array}{l}\text { - Rates of screen failure defined as the } \\
\text { percentage of participants screened } \\
\text { who failed screening } \\
\text { - Completion and discontinuation of } \\
\text { treatment, defined as the percentage } \\
\text { of participants who completed treatment/ } \\
\text { percentage of participants who } \\
\text { discontinued treatment } \\
\text { - Completion / discontinuation of } \\
\text { follow-up, defined as the } \\
\text { percentage who completed } \\
\text { follow-up/ percentage who } \\
\text { discontinued follow-up }\end{array}$ & • Treatment adherence (B) \\
\hline $\begin{array}{l}\text { Khatawkar } 2014 \\
{[19]}\end{array}$ & $\begin{array}{l}\text { Retrospective analysis of data queries } \\
\text { using clinical trial data }\end{array}$ & Not applicable & $\begin{array}{l}\text { - Data query }(D Q) \text { rate per page } \\
\text { - DQ rate per page by phase of study }\end{array}$ & $\begin{array}{l}\text { - DQ rate per page by country }(B) \\
\text { - DQ rate per page by therapeutic } \\
\text { area (B) }\end{array}$ \\
\hline Lee 2012 [20] & $\begin{array}{l}\text { Paper describing the output of a } \\
\text { Delphi survey to establish an } \\
\text { 'evaluation framework' for clinical } \\
\text { trial data }\end{array}$ & Not applicable & $\begin{array}{l}\text { - Rapid enrolment, defined as } \\
\text { time taken to reach target } \\
\text { enrolment } \\
\text { - Timely data entry, defined as } \\
\text { time taken for data entry after } \\
\text { completion of informed consent } \\
\text { - Timely manual query management, } \\
\text { defined as time taken for response } \\
\text { to manual query request from data centre } \\
\text { - Timely database lock, defined as }\end{array}$ & $\begin{array}{l}\text { - Weeks after go-live, i.e. after the } \\
\text { point of protocol amendment (A) }\end{array}$ \\
\hline
\end{tabular}


Table 1 Characteristics of included studies (Continued)

\begin{tabular}{ll}
\hline Study & Study description \\
\hline & \\
& \\
& \\
Rojavin, 2005 & $\begin{array}{l}\text { Paper describing and discussing one } \\
\text { proposed metric }\end{array}$ \\
& \\
& \\
Rosendorf, 1993 & $\begin{array}{l}\text { Trials of treatment for HIV. No further } \\
\text { details. An evaluation tool was proposed } \\
\text { to monitor individual site performance } \\
\text { within a multicentre randomised trial. }\end{array}$ \\
&
\end{tabular}

Number of sites Metrics reported by each study

(sample size) Included as site performance metric

time taken for database lock

after the last visit of last

participant per site

- Data discrepancy management metric encompassing number of manual queries per CRF for missing data; number of manual queries per CRF for out -of-range data; number of manual queries per CRF for logical consistency

- Protocol compliance metric encompassing: rate of 'dropout' of total participants; rate of false 'dropout' of total dropouts; rate of late detection of 'dropout' - Enrolment success defined as \% eligible per study

Not applicable $\quad$ - Recruitment Index (RI) $=($ LPFV FPFV) $\times$ S/P where LPFV $=$ date of the last participant first visit

$F P F V=$ date of the first participant first visit

$S=$ number of participating sites

$\mathrm{P}=$ number of participants who successfully completed the study

59 (ns) Intensity adjusted score (IAS) = IAS = ISO + don $\times 1 S 1+$ doff $\times 1 S 2$ where: $\mathrm{ISO}=$ score assigned for enrolling a new participant during the 6 month evaluation period don $=$ number of days the participant was on the study medication during the evaluation period

doff = number of days the participant was off the study medication

IS1 = intensity score for the days

in which the participant is receiving study medication IS2 = intensity score for the days in which the participant is off all study medication

ISA is calculated for each participant and then summing scores across all participants, once during

the evaluation period

- Funding adjusted score $=$ IAS divided by the amount awarded for total direct costs during the given time period - Summary quartiles = total number of new and continuing participants on study

Sweetman, 2011 Retrospective analysis of publications of [23] 80 clinical trials on protocol violations reporting

Thom, 2011 Report of a centre performance assessment tool used within a clinical trial network to assess individual site performance
Paper describing monitoring methods using a 'risk proportionate approach' used by an individual clinical trials unit
Not applicable Occurrence of protocol violations, defined as total number of protocol violations divided by the number of enrolled participants

Not applicable - Protocol adherence, defined as average rate of protocol violations per enrolled participant - Data quality, defined as average rate of edit checks per participant

- Data timeliness, defined as the percentage of forms entered late

- Time of starting after the first centre start date

- Sum of protocol adherence, data quality, data timeliness and timeliness of study start-up to give overall rank

- Timeliness of study start-up

Not applicable • Consent form completion, defined as consent forms returned within 7 days of completion by sites.
Excluded as not site performance metric ${ }^{a}$ 
Table 1 Characteristics of included studies (Continued)

\begin{tabular}{l} 
Study \\
\hline
\end{tabular}
of monitoring the conduct of trials

Studies using performance metrics
Berthon-Jones 2015 [2]

Katz, $2015[26]$

Kim, $2011[27]^{a}$

Rifkind, 1983 [28]
Aim of main study: treatment-naïve HIV patients randomised to 2 different types of ART. Primary outcome plasma HIV-RNA, change from baseline to week 48. Performance across 5 geographical regions was assessed using performance metrics
Number of sites Metrics reported by each study

(sample size) Included as site performance metric

- Recruitment process, defined as frequency of eligible participants who do not provide consent.

- Missing primary outcome data, defined as cumulative percentage of participants with missing primary outcome data at each site - SAEs, defined as cumulative percentage of participants with at least one SAE across the trial as a whole and at each site /measure of time, e.g. 1 month

- Sum of all SAEs/sum of all follow-up for the trial

- Sum of all follow-up at site x overall SAE rate for the trial

- Visit dates, defined as time between actual date of visit versus expected date of visit

Not applicable • Quality metric encompassing: average number of major audit findings per audited site; percentage per site of unreported, confirmed SAEs; number of significant protocol deviations per site - Frequency of protocol violations for eligibility criteria and randomisation per site

- Rates of withdrawal by site

$36(322)$

- Time from protocol release to ethics/ regulatory submission

- Time from protocol release to ethics/ regulatory approval

- Time from protocol release to first participant randomised (FPR)

- Time from protocol release to last participant randomised (LPR)

- Time from site opened to first participant randomised (FPR)

- Time from first participant randomised (FPR)

to last participant randomised (LPR)

- Actual versus estimated recruitment

- Time from participant visit to electronic data capture (EDC) initiation

- Time from EDC initiation to completion - Number of missing values per participant

- Number of data queries per participant

- Number of SAEs reported per participant

- Time from SAE occurrence to initial report

- Time from initial SAE report to final report

- Number of samples collected versus number required by protocol

40-88 (91-157) · Time to data query response

- Compliance with study drug (D)
- Proportion of the enrolled population comprising the nonrandomised parallel cohorts (measured by percentage agreement and kappa statistic) (O) - Radiologic inter-observer agreement (C)

- Number of missed visits per region (B)

- Quality of laboratory sample/s collected (A)

- Number of plasma samples collected versus protocolmandated samples to be collected (C)

- Number of buffy-coat samples collected versus protocolmandated samples to be collected (C) (2 trials), lower back pain (1 trial) randomised to fulranumab infusion or placebo. Primary outcomes unspecified. Within these three clinical trials a method of monitoring individual site performance was applied

Aim of main study: patients with acute cerebral haemorrhage randomised to early intensive antihypertensive or standard regimen. Primary outcome death or disability at 3 months. A site performance monitoring tool was incorporated for monitoring individual site performance during the trial

- Participant recruitment per site - CRF data collection timeliness + completeness

- Protocol violations per site

- SAE reporting per site

- Participant study progress (A)

- Site data monitoring visit findings (A) - Data clarification request processing (A)

- Regulatory document collection and tracking (A) thyper-lipoproteinaemia randomised
12 (3550) - Proportion of initial contacts proceeding to first protocol visit by recruitment source - Proportion of first protoco visits proceeding to study entry by recruitment source to bile acid sequestrant or placebo. Primary outcome CHD death and/or nonfatal myocardial infarction. Within this study measures of individual site recruitment performance were monitored. 
Table 1 Characteristics of included studies (Continued)

\begin{tabular}{|c|c|c|c|c|}
\hline \multirow[t]{2}{*}{ Study } & \multirow[t]{2}{*}{ Study description } & \multirow{2}{*}{$\begin{array}{l}\text { Number of sites } \\
\text { (sample size) }\end{array}$} & \multicolumn{2}{|l|}{ Metrics reported by each study } \\
\hline & & & $\begin{array}{l}\text { Included as site performance } \\
\text { metric }\end{array}$ & Excluded as not site performance metric ${ }^{a}$ \\
\hline $\begin{array}{l}\text { Saunders, } 2015 \\
{[29]^{\mathrm{a}}}\end{array}$ & $\begin{array}{l}\text { Aim of the main study: critical care } \\
\text { patients randomised to probiotic or } \\
\text { placebo. Primary outcome ventilator } \\
\text { associated pneumonia. Within this } \\
\text { study the team focused on screening } \\
\text { performance in individual centres }\end{array}$ & $14(285)$ & $\begin{array}{l}\text { - Non-screening weeks = proportion } \\
\text { of weeks during which participants } \\
\text { were not screened for trial eligibility }\end{array}$ & $\cdot$ \\
\hline Sun, 2008 [30] & $\begin{array}{l}\text { Aim of the main study: patients with } \\
\text { major depression randomised to } \\
\text { aprepitant or placebo. Primary } \\
\text { outcome change in Hamilton } \\
\text { Depression Scale. Within this } \\
\text { study measures of individual site } \\
\text { performance were captured }\end{array}$ & Not reported & $\begin{array}{l}\text { - Administration excellence, defined } \\
\text { as site administration performance } \\
\text { and interaction with central study } \\
\text { team rated } 1,2 \text { or } 3 \\
\text { - Data quality, defined as data } \\
\text { completeness and correctness at } \\
\text { initial submission rated } 1,2 \text {, or } 3 \\
\text { - Proportion of participants with } \\
\text { protocol violation, defined as: } \\
\text { proportion of participants in } \\
\text { each site who do not meet } \\
\text { eligibility criteria; have medication } \\
\text { compliance }<75 \% \text {, or take prohibited } \\
\text { concomitant medication or wrong } \\
\text { study medication; or other serious } \\
\text { violation } \\
\text { - Level of visit non-compliance, } \\
\text { defined as mean absolute } \\
\text { difference of the days between } \\
\text { visits and the protocol-specified } \\
\text { days between visits for participants } \\
\text { in a specific centre }\end{array}$ & $\begin{array}{l}\text { - Level of medication non-compliance, de } \\
\text { number of doses of study-assigned med }\end{array}$ \\
\hline Wear, $2010[31]^{a}$ & $\begin{array}{l}\text { Aim of the main study: patients } \\
\text { with multiple myeloma, multiple } \\
\text { clinical trials. No further details. } \\
\text { Performance metrics utilised } \\
\text { during the study }\end{array}$ & Not reported & $\begin{array}{l}\text { - First patient dosed (FPD), defined } \\
\text { as time from receipt of final protocol } \\
\text { to the first participant treated } \\
\text { - Enrolment commitment (EC), defined } \\
\text { as commitment from the study site to } \\
\text { provide a predicted number of } \\
\text { participants who will receive at least } \\
1 \text { dose of study drug (e.g. number } \\
\text { of participants randomised and } \\
\text { completing first part of intervention } \\
\text { - Baseline enrolment timeline (BET), } \\
\text { defined as target time period to obtain EC }\end{array}$ & \\
\hline
\end{tabular}

$A E$ adverse event; $A R T$ antiretroviral therapy; $C H D$ coronary heart disease; $C R F$ case record form; $C T U$ clinical trial unit; $n s$ not specified; $S A E$ serious adverse event; VTE venous thromboembolism

aExcluded due to (a) lack of clarity, (b) not related to individual site performance, (c) too specific to an individual trial methodology, (d) pertaining to clinical outcomes not trial performance

${ }^{\mathrm{b}}$ It is unclear from the paper whether enrolment refers to participants randomised to a study or simply consented and then screened for study eligibility

\section{Search strategy}

We searched the Cochrane Library and five biomedical bibliographic databases (CINAHL, Excerpta Medica database (EMBASE), Medical Literature Analysis and Retrieval System Online (Medline), Psychological Information Database (PsychINFO) and SCOPUS) and Google Scholar from 1980 to 2017 week 07 . The search strategy is provided as an Appendix (Table 3).

\section{Selection of studies}

Two reviewers (KW, JT) independently assessed for inclusion the titles and abstracts identified by the search strategy. If there was disagreement about whether a record should be included, we obtained the full text.

We sought full-text copies for all potentially eligible records, and two reviewers (KW, JT) independently assessed these for inclusion. Disagreements were resolved by discussion, and if agreement could not be reached the study was independently assessed by a third reviewer (LD). Multiple reports of the same study were linked together.

\section{Data extraction and data entry}

Two reviewers (KW, JT) extracted data independently onto a specifically designed data extraction form. In the few cases where full text was not available $(n=9)$, data were extracted using the title and abstract only. Data were entered into an Excel spreadsheet, and checked.

Data were extracted on the design of the randomised trial (participants, intervention, control, number of sites and target sample size); whether the performance metric/s was theoretical or applied. For each performance metric we collected data that included: a verbatim description of the metric; how the metric was measured or expressed; timing of the measurement and during which phase of the study; 
Table 2 Examples of performance metrics within each identified

\begin{tabular}{|c|c|c|}
\hline Categories & $\begin{array}{l}\text { Example performance } \\
\text { metric }\end{array}$ & $\begin{array}{l}\text { Studies in which } \\
\text { metric included }\end{array}$ \\
\hline Assessing site potential & $\begin{array}{l}\text { Site location potential index } \\
\text { based on an assessment of } \\
\text { the number of patients at } \\
\text { an individual site with the } \\
\text { disease of interest }\end{array}$ & [14] \\
\hline $\begin{array}{l}\text { Monitoring } \\
\text { recruitment }\end{array}$ & $\begin{array}{l}\text { Number of participants } \\
\text { randomised per site }\end{array}$ & {$[15,17,27]$} \\
\hline Monitoring retention & Rates of withdrawal by site & {$[20,25]$} \\
\hline $\begin{array}{l}\text { Quality of data } \\
\text { collection }\end{array}$ & $\begin{array}{l}\text { Number of data queries } \\
\text { per participant }\end{array}$ & {$[2,12,19]$} \\
\hline Trial conduct & $\begin{array}{l}\text { Protocol violations per site } \\
\text { or per participant }\end{array}$ & {$[12,15,23,27,30]$} \\
\hline Trial safety & $\begin{array}{l}\text { Serious adverse event } \\
\text { (SAE) reporting } \\
\text { per site }\end{array}$ & {$[11,24,27]$} \\
\hline
\end{tabular}

who measured the metric; if a threshold exists to trigger action, what the threshold was and what action it triggers; and whether the metric was recommended by the authors.

\section{Data analysis}

We described the flow of studies through the review, with reasons for being removed or excluded, using the Preferred Reporting Items for Systematic Reviews and Meta-Analyses (PRISMA) guidance [10]. Characteristics of each study were described and tabulated. Analyses were descriptive only, with no statistical analyses anticipated.

\section{Results}

The database search identified 3365 records, of which 177 were duplicates, leaving 3188 screened for eligibility (Fig. 1). At screening, we obtained full-text copies for 147 records to determine eligibility. For a further seven records full-text copies were unavailable, and so screened was based on the abstract only. Of those full-text copies and abstracts (for papers where the full text was unavailable), there was disagreement on three papers. Following discussion two papers were accepted for inclusion [11, 12] and one paper was excluded [13].

Twenty-one studies were agreed for inclusion, of which 14 were studies proposing performance metrics and seven were studies using performance metrics (Table 1). These 21 studies reported a total of 117 performance metrics. The median number of performance metrics reported per study was 8 , with the range being 1-16. Those 117 metrics were then screened, to exclude any judged as: lacking sufficient clarity; being unrelated to individual site performance; being too specific to an individual trial methodology or pertaining to clinical outcomes not trial performance. This left 87 performance metrics to be considered for use in day-to-day trial management. The metrics broadly fell into six main categories: assessing site potential before recruitment starts; and monitoring recruitment, retention, quality of data collection, quality of trial conduct, and trial safety (Table 2).

\section{Discussion}

As far as we are aware, this is the first systematic review to identify and describe proposed or utilised metrics to monitor site performance in multicentre randomised trials. It provides a list of performance metrics, which can be used to contribute to developing and agreed a proposed set of performance metrics for use in day-to-day trial management. We identified 87 performance metrics which fell broadly into six main categories.

A strength of our study was the comprehensive search of the literature.

In planning this systematic review we envisaged that studies would be identified that had evaluated individual performance metrics either by implementation mid-way through a study, or ideally by randomising individual sites to use of a particular metric or not. Unfortunately, there was a paucity of such studies. Most studies suggested performance metrics on a purely theoretical basis, and did not provide data on the actual use of suggested metrics. The main limitations of our study were the lack of studies implementing performance metrics and reporting the effects of their utilisation, and that published work on this topic is limited, which is perhaps surprising as informal assessment of how sites perform in multicentre trials is common.

This list of performance metrics contributed to development of a Delphi survey sent to trial managers, UKCRC CTU directors and key clinical trial stakeholders, which is reported elsewhere. They were invited to participate through the UK Trial Managers' Network (UK TMN) and UK Clinical Research Collaboration (UKCRC CTU) Network. Three Delphi rounds were used to steer the groups to consensus, refining the list of performance metrics. The reasons for their decisions were documented. Finally, data from the Delphi survey was presented to stakeholders in a priority setting expert workshop, providing participants with the opportunity to express their views, hear different perspectives and think more widely about monitoring of site performance. This was used to establish a consensus among experts on the top key performance metrics, expected to number around 8-12.

\section{Conclusions}

This study provides trialists for the first time with a comprehensive description of performance metrics described in the literature that have been proposed or used in the context of multicentre randomised trials. It will assist future work to develop a concise, practical list of performance metrics which could be used in day-to-day trial management to improve the performance of individual sites. This has the potential to reduce both the financial cost of delivering a multicentre trial, and the research waste and delay in scientific progress that results when trials fail to meet their recruitment target, are poorly conducted, or have inadequate data. 


\section{Appendix}

Table 3 Search strategy. Monitoring performance of sites within multicentre randomised trials: a systematic review of performance metrics

\begin{tabular}{|c|c|c|c|}
\hline \multirow{2}{*}{\multicolumn{2}{|c|}{ metrics }} & \\
\hline & & \# & Searches \\
\hline \# & Searches & 40 & 39 and 5 \\
\hline 1 & Randomised. controlled trial & 41 & 40 Not (animals/ not humans.sh. \\
\hline 2 & Clinical trial & 42 & 40 \\
\hline 3 & Pragmatic trial & 43 & Limit 42 to English language \\
\hline
\end{tabular}

\section{Controlled clinical trial}

1 or 2 or 3 or 4

Performance indicator

Performance metric

Performance measure

Enrollment rate

Participant enrollment

Participant recruitment

Quality indicator

Quality measure

Performance management

Assessing site performance

Central monitoring

Clinical trial monitoring

Clinical trial reporting

Trial analytics

Trial management

Site performance

Study conduct

Trial site performance

Benchmarking performance

Clinical data management

Clinical trial data quality

Laboratory sample quality in clinical trials

Operational metrics

Operational performance

Performance evaluation

Performance monitoring

Performance score

Protocol deviations

Protocol violations

Quality management system

Recruitment index

Screening logs

Strategic project management

6 or 7 or 8 or 9 or 10 or 11 or 12 or 13 or 14 or 15 or 16 or 17 or 18 or 19

or 20 or 21 or 22 or 23 or 24 or 25 or 26

or 27 or 28 or 29 or 30 or 31 or 32

or 33 or 34 or 35 or 36 or 37 or 38
Table 3 Search strategy. Monitoring performance of sites within multicentre randomised trials: a systematic review of performance metrics (Continued)

\section{Abbreviations}

CINAHL: Cumulative Index to Nursing and Allied Healthy Literature; CRF: Case report form; CTUs: Clinical Trials Units; EMBASE: Excerpta Medica database; Medline: Medical Literature Analysis and Retrieval System Online; NIHR: National Institute for Health Research; PRISMA: Preferred Reporting Items for Systematic Reviews and Meta-Analyses; PsychINFO: Psychological Information Database; UK TMN: UK Trial Managers' Network; UKCRC: UK Clinical Research Collaboration

\section{Funding}

This work was funded by NIHR CTU Support funding. The views expressed are those of the author(s) and not necessarily those of the National Health Service (NHS), the National Institute for Health Research (NIHR) or the Department of Health.

\section{Availability of data and materials}

The datasets used and/or analysed during the current study are available from the corresponding author on reasonable request.

\section{Authors' contributions}

LD and DW conceived the study. LD, DW, JT, KW and AM designed the study and wrote the protocol. JT and KW performed the search and collected the data. KW analysed the data and drafted the paper with input from LD and JT. All authors read and approved the final manuscript.

Ethics approval and consent to participate

Not applicable.

\section{Consent for publication}

Not applicable.

\section{Competing interests}

The authors declare that they have no competing interests.

\section{Publisher's Note}

Springer Nature remains neutral with regard to jurisdictional claims in published maps and institutional affiliations.

Received: 15 May 2018 Accepted: 26 September 2018

Published online: 16 October 2018

\section{References}

1. Duley L, Antman K, Arena J, Avezum A, Blumenthal M, Bosch J, Chrolavicius $\mathrm{S}, \mathrm{Li}$ T, Ounpuu S, Perez AC, et al. Specific barriers to the conduct of randomized trials. Clin Trials. 2008;5(1):40-8.

2. Berthon-Jones N, Courtney-Vega K, Donaldson A, Haskelberg H, Emery S, Puls R. Assessing site performance in the Altair study, a multinational clinical trial. Trials. 2015;16(1):138 (no pagination).

3. Coleby D, Whitham D, Duley L. Can site performance be predicted? Results of an evaluation of the performance of a site selection questionnaire in five multicentre trials. Trials. 2015;16(Suppl 2):176.

4. Kirkwood AA, Cox T, Hackshaw A. Application of methods for central statistical monitoring in clinical trials. Clin Trials. 2013;10(5):783-806.

5. Bakobaki JM, Rauchenberger M, Joffe N, et al. The potential for central monitoring techniques to replace on-site monitoring: Findings from an international multi-centre clinical trial. Clin Trials 2012;9:257-64. 
6. Timmermans C, Venet D, Burzykowski T. Data-driven risk identification in phase III clinical trials using central statistical monitoring. Int J Clin Oncol. 2016;21(1):38-45.

7. Tantsyura V, Dunn IM, Fendt K, Kim YJ, Waters J, Mitchel J. Risk-based monitoring: a closer statistical look at source document verification, queries, study size effects, and data quality. Ther Innov Regul Sci. 2015;49(6):903-10.

8. Smith B, Martin L, Martin S, Denslow M, Hutchens M, Hawkins C, Panier V, Ringel MS. What drives site performance in clinical trials? Nat Rev Drug Discov. 2018;17(6):389-90.

9. Dorricott K. Using metrics to direct performance improvement efforts in clinical trial management. Monitor. 2012;26(4):9-13.

10. Moher D, Liberati A, Tetzlaff J, Altman DG, Grp P. Preferred Reporting Items for Systematic Reviews and Meta-Analyses: the PRISMA Statement. J Clin Epidemiol. 2009;62(10):1006-12.

11. Hanna M, Minga A, Fao P, Borand L, Diouf A, Mben JM, Gad RR, Anglaret X, Bazin $B$, Chene G. Development of a checklist of quality indicators for clinical trials in resource-limited countries: The French National Agency for Research on AIDS and Viral Hepatitis (ANRS) experience. Clin Trials. 2013;10(2):300-18.

12. Thom E. A center performance assessment tool in a multicenter clinical trials network. Clin Trials. 2011;8(4):519.

13. Hullsiek KH, Wyman N, Kagan J, Grarup J, Carey C, Hudson F, Finley E, Belloso W. Design of an international cluster-randomized trial comparing two data monitoring practices. Clin Trials. 2013;10:532-3.

14. Bose A, Das S. Trial analytics - A tool for clinical trial management. Acta Poloniae Pharmaceutica - Drug Research. 2012;69(3):523-33.

15. Djali S, Janssens S, Van Yper S, Van Parijs J. How a data-driven quality management system can manage compliance risk in clinical trials. Drug Inform J. 2010;44(4):359-73.

16. Elsa VM, Jemma HC, Martin L, Jane A. A key risk indicator approach to central statistical monitoring in multicentre clinical trials: method development in the context of an ongoing large-scale randomized trial. Trials Conference: Clinical Trials Methodology Conference. 2011;12:1.

17. Glass HE, DiFrancesco JJ. Understanding site performance differences in multinational phase III clinical trials. Int J Pharmaceutical Med. 2007;21 (4):279-86.

18. Jou JH, Sulkowski MS, Noviello S, Long J, Pedicone LD, McHutchison JG, Muir AJ. Analysis of site performance in academic-based and communitybased centers in the IDEAL study. J Clin Gastroenterol. 2013;47(10):e91-5.

19. Khatawkar S, Bhatt A, Shetty R, Dsilva P. Analysis of data query as parameter of quality. Perspect Clin Res. 2014;5(3):121-4.

20. Lee HJ, Lee S. An exploratory evaluation framework for e-clinical data management performance. Drug Inf J. 2012;46(5):555-64.

21. Rojavin MA. Recruitment index as a measure of patient recruitment activity in clinical trials. Contemp Clin Trials. 2005;26(5):552-6.

22. Rosendorf LL, Dafni U, Amato DA, Lunghofer B, Bartlett JG, Leedom JM, Wara DW, Armstrong JA, Godfrey E, Sukkestad E, et al. Performance evaluation in multicenter clinical trials: Development of a model by the AIDS Clinical Trials Group. Control Clin Trials. 1993;14(6):523-37.

23. Sweetman EA, Doig GS. Failure to report protocol violations in clinical trials: a threat to internal validity? Trials. 2011;12:214 (no pagination).

24. Tudur Smith C, Williamson P, Jones A, Smyth A, Hewer SL, Gamble C. Riskproportionate clinical trial monitoring: an example approach from a noncommercial trials unit. Trials. 2014;15(1):127 (no pagination).

25. Wilson B, Provencher T, Gough J, Clark S, Abdrachitov R, de Roeck K, Constantine SJ, Knepper D, Lawton A. Defining a central monitoring capability: sharing the experience of TransCelerate BioPharma's approach, Part 1. Ther Innov Regul Sci. 2014;48(5):529-35.

26. Katz N. Development and validation of a clinical trial data surveillance method to improve assay sensitivity in clinical trials. J Pain. 2015;1:S88,

27. Kim J, Zhao W, Pauls K, Goddard T. Integration of site performance monitoring module in web-based CTMS for a global trial. Clin Trials. 2011;8(4):450.

28. Rifkind BM. Participant recruitment to the coronary primary prevention trial. J Chronic Dis. 1983;36(6):451-65.

29. Saunders L, Clarke F, Hand L, Jakab M, Watpool I, Good J, Heels-Ansdell D. Screening weeks: a pilot trial management metric. Crit Care Med. 2015;1:330.

30. Sun J, Wang J, Liu G. Evaluation of the quality of investigative centers using clinical ratings and compliance data. Contemp Clin Trials. 2008;29(2):252-8,

31. Wear S, Richardson PG, Revta C, Vij R, Fiala M, Lonial S, Francis D, DiCapua Siegel DS, Schramm A, Jakubowiak AJ, et al. The multiple myeloma research consortium (MMRC) model: Reduced time to trial activation and improved accrual metrics. Blood Conference: 52nd Annual Meeting of the American Society of Hematology, ASH. 2010;116(21):3803.

\section{Ready to submit your research? Choose BMC and benefit from:}

- fast, convenient online submission

- thorough peer review by experienced researchers in your field

- rapid publication on acceptance

- support for research data, including large and complex data types

- gold Open Access which fosters wider collaboration and increased citations

- maximum visibility for your research: over $100 \mathrm{M}$ website views per year

At BMC, research is always in progress.

Learn more biomedcentral.com/submissions 